\title{
RECUPERAÇÃO DAS MATAS CILIARES E DE ÁREAS DE FEIÇÕES EROSIVAS NA BACIA DO BOM JARDIM, BRASILÂNDIA/MS
}

Gabrielle Alberta Pereira ${ }^{1}$

André Luiz Pinto ${ }^{2}$

\section{Introdução}

Preocupado com os problemas, devido as mudanças no meio ambiente e na natureza, no Brasil e em todo mundo se tem usado a bacia hidrográfica como principal objeto de estudo e planejamento.

A escassez de água não pode mais ser considerada como atributo exclusivo de regiões áridas e semi-áridas. Muitas áreas com recursos hídricos abundantes, mas insuficientes para atender a demandas excessivamente elevadas, também experimentam conflitos de usos e sofrem restrições de consumo que afetam o desenvolvimento econômico e a qualidade de vida (TUNDISI, 2003).

Para restabelecer o equilíbrio entre oferta e demanda de água e garantir a sustentabilidade do desenvolvimento econômico e social, é necessário que métodos e sistemas alternativos modernos sejam convenientemente desenvolvidos e aplicados em função de características de sistemas e centros de produção específicos. Nesse sentido, reuso reciclagem, gestão da

\footnotetext{
${ }^{1}$ Bacharel em Geografia, da UFMS/CPTL

${ }^{2}$ Professor Doutor Associado II da UFMS/CPTL
} 
demanda, redução de perdas e minimização da geração de efluentes se constitui em associação às práticas conservacionistas, nas palavras-chave mais importantes em termos de gestão de recursos hídricos e de redução da poluição.

A Lei № 9.433 de 8 de janeiro de 1997 vem contemplar a importância da bacia hidrográfica, em seu principio primeiro: a adoção da bacia hidrográfica como unidade de planejamento, tendo como limites da bacia o perímetro da área a ser planejada.

Para Rocha et.al (2000) qualquer tipo de uso do solo na bacia hidrográfica interfere no ciclo hidrológico, não importando o grau com que esse tipo de uso utiliza ou dependa diretamente da água. Pode ser verificado, por exemplo, que, embora a agricultura sem irrigação não retire água de um manancial superficial, sua presença interfere de forma indireta na erosão, com o aumento do escoamento superficial e consequentemente assoreamento dos corpos d'água, na redução da taxa de infiltração de água no solo, na diminuição do lençol freático, na alteração do padrão da vazão dos córregos etc. desde que o uso do recurso solo interfira no recurso água (PIRES e SANTOS, 1995).

Contudo tanto o uso e ocupação e manejo do solo das bacias influência na dinâmica do escoamento superficial, propiciando graus diferenciados de resistência às ações dos agentes externos e processo que modelam a sua morfologia, e consecutivamente os transportes de materiais que inter vem na qualidade da água desse manancial.

"Se as formas de relevo constituem - se no substrato físico para as instalações humanas, elas também sofrem modificações causadas por tais instalações e respondem as tais alterações, muitas vezes de forma agressiva". Assim, Casseti (1994), ao referir-se a este problema, afirma que "mesmo a ação indireta do homem, ao eliminar a interface - representada pela cobertura vegetal - alteram de forma substancial as relações entre as forças de ação (processo morfodinâmicos) e de reação da formação superficial ou mesmo do substrato, implicando em desequilíbrios morfológicos, e muitas vezes tendo 
conseqüências geoambientais (movimentos de massa, boçorocamento, assoreamento...) que chegam a ser catastróficas"

As drenagens fluviais são um conjunto de canais de escoamento interrelacionados e que formam a bacia de drenagem, que é definida como a área drenada por um determinado rio ou por um sistema fluvial.

A bacia do córrego Bom Jardim foi escolhida devido a necessidade de conservação e recuperação da mata ciliar e pelas quantidades de erosões que ocorrem na bacia, e por outros fatores como, se localizar na reserva Cisalpina, a aldeia Ofayé e ser afluente do rio Paraná.

Serão elaborados estudos que apontaram áreas onde devam ser recuperadas as matas ciliares e áreas expostas a feições erosivas, que colocam em risco as atividades produtivas na bacia. Bem como, serão recomendadas em áreas especificas a implantação de práticas conservacionistas de uso, ocupação e manejo da terra.

Para a operacionalização da pesquisa serão analisados os padrões de drenagens fluviais da bacia, através do emprego de diversas propostas metodológicas para a construção de cartas morfométricas,

\section{Objetivos}

Propor mecanismos de recuperação das matas ciliares e das feições erosivas, visando à redução da perda de solo, produtividade, do assoreamento e da quantidade/qualidade de suas águas, e a certificação de produção ambientalmente correta na bacia.

\section{Localização e Caracterização da Área}

O Município de Brasilândia localiza-se nas imediações do eixo da Sinéclise do Paraná, no Estado de Mato Grosso do Sul, possui uma área de aproximadamente $5.000 \mathrm{Km}^{2}$. Situa-se entre as coordenadas geográficas 


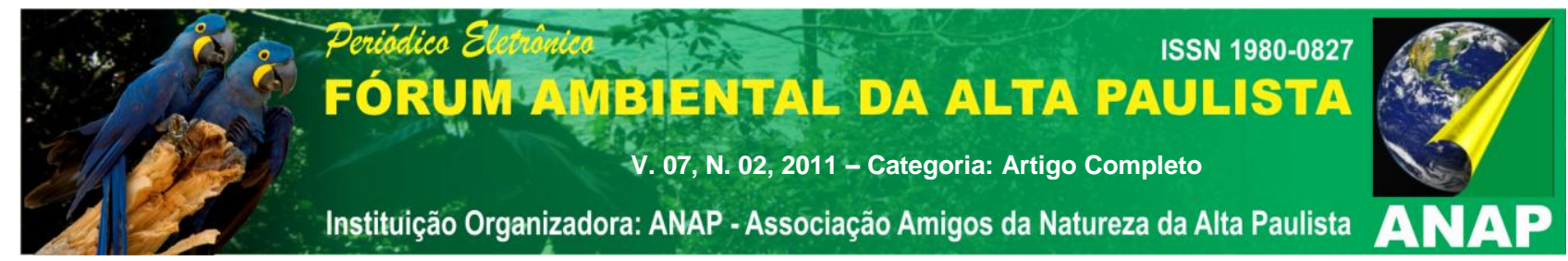

$20^{\circ} 45^{\prime}$ e $21^{\circ} 34^{\prime}$ S e $51^{\circ} 51^{\prime}$ e $52^{\circ} 56^{\prime} \mathrm{W}$, região drenada por inúmeras microbacias que fluem para o Rio Paraná. A bacia do Córrego Bom Jardim localiza-se entre as coordenadas geográficas de $21^{\circ} 15^{\prime}$ e $21^{\circ} 18^{\prime} \mathrm{S}$ e $52^{\circ} 07^{\prime}$ e $51^{\circ} 58^{\prime} \mathrm{W}$; abrange uma área de aproximadamente $25 \mathrm{Km}^{2}$, que drena terrenos do Planalto Arenítico-Basáltico Interiores, de idade cretácea, do Grupo Bauru, Formação Santo Anastácio. Nesse o arcabouço litológico predominante são arenitos, aos quais sobre põem-se pacotes colúvio-aluvionares recentes, status que predomina entre os $12 \mathrm{Km}$ que separam o núcleo urbano brasilandense da calha do Rio Paraná (Figura 01).

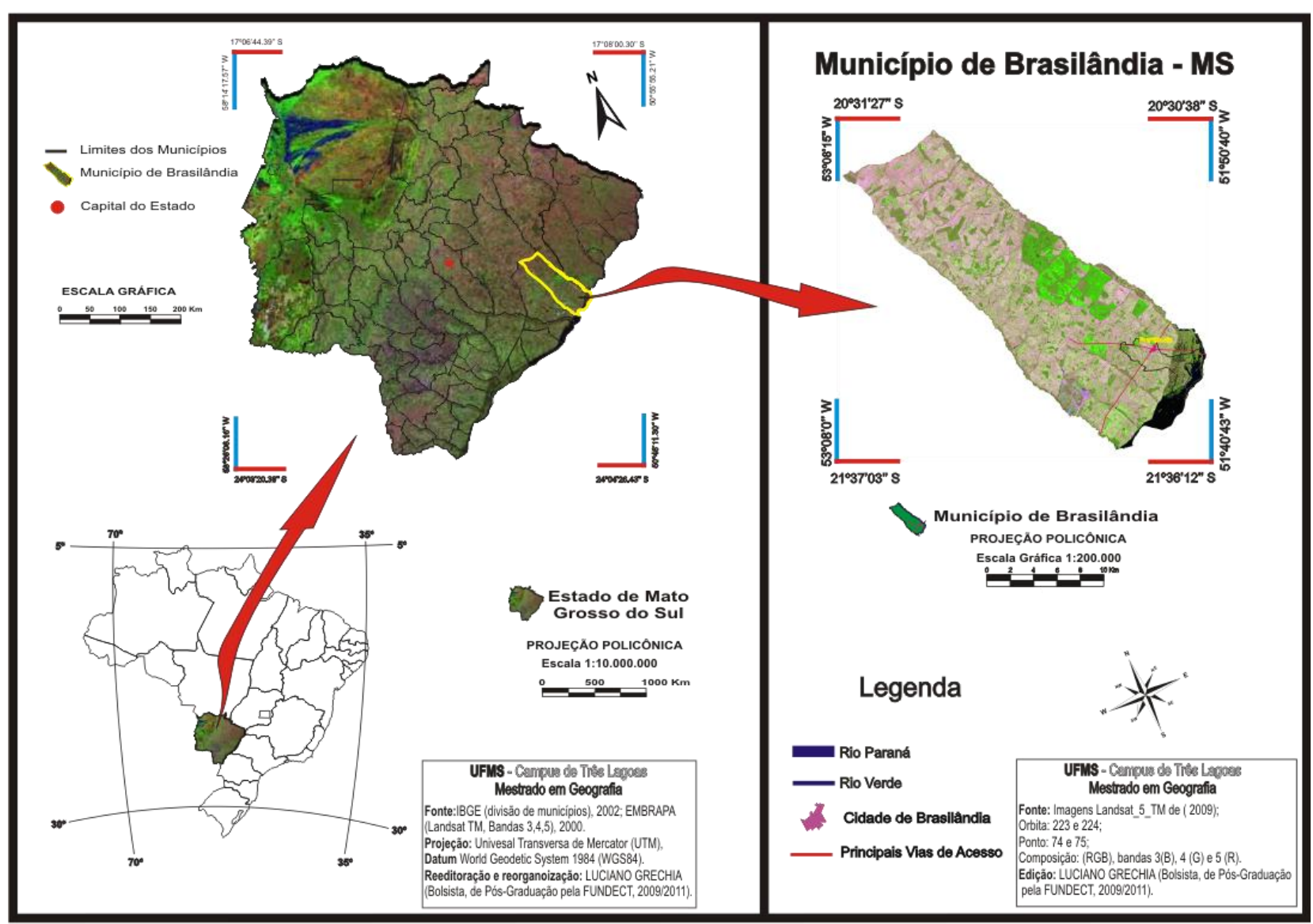

Figura 1: Mapa de Localização do município de Brasilândia - MS 


\section{Caracterização da Área}

O clima do Município de Brasilândia possui duas estações bem definidas, a chuvosa e a seca, que segundo a classificação de Koppen é o Aw, definido como clima tropical úmido. A precipitação média anual dessa região está em torno de $1300 \mathrm{~mm}$. O período chuvoso normalmente prolonga-se por seis meses, de outubro a março, sendo os meses de dezembro e janeiro com $30 \%$ de precipitação total, e uma estação definida nos meses de junho, julho e agosto, quando remontam apenas cerca de $6 \%$ de precipitação anual (PINTO, 2006).

Geralmente a média térmica da região é alta, ficando em torno de $23,7^{\circ} \mathrm{C}$, enquanto a média mensal do mês mais quente (fevereiro) alcança $26,4^{\circ} \mathrm{C}$ e a do mês mais frio (julho) chegam a 19,4 $\mathrm{C}$. Entretanto, são comuns na região temperaturas superiores a $30^{\circ}$ e nos meses de inverno, temperaturas mínimas de menos de $14^{\circ} \mathrm{C}$.

O município de Brasilândia situa-se no alto curso da Bacia do rio Paraná, ocupando uma área de $5.000 \mathrm{Km}^{2}$, aproximadamente, na porção leste do estado de Mato Grosso do Sul, tendo como principal tributário o rio Verde, que limita a área da reserva CISALPINA, em seu lado direito.

As nascentes da Bacia do rio Bom Jardim localizam - se nas fazendas Bom Jardim e São Paulo, com altitude em torno de 400 metros, percorrendo áreas de Planalto e da Planície Aluvionar do Paraná, por 14 Km até sua Foz no rio Paraná, drenando área de $25 \mathrm{Km}^{2}$ (Figura 01).

A Bacia do córrego Bom Jardim esta situada numa área de Domínio do Aqüífero da Bacia Sedimentar do Paraná (Brasil), Aqüífero Guarani, que compreende o sistema de aqüíferos Bauru - Caiuá, Serra Geral, Botucatu Pirambóia - rio do Rastro e Aquidauana com um volume estocado de água de $50.400 \mathrm{Km}^{3}$. 
A Bacia do córrego Bom Jardim encontra-se geologicamente disposta sobre terrenos cretáceos do Grupo Bauru, Formação Santo Anastácio, compostos por arenitos bastante porosos, facilmente desagregados, freqüentemente laterizados, onde repousam espesso e constante solo arenoso (ATLAS MULTIREFERENCIAL, 1990).

Segundo o Atlas Multirreferencial (1990), a Bacia do Córrego Bom Jardim drena terrenos sotopostos por arenitos dos Grupos Caiuá e Bauru (Formações Santo Anastácio e Adamantina). Essas unidades litoestratigráficas caracterizam-se por alta porosidade e permeabilidade e a grande facilidade de desagregação. Os Arenitos Santo Anastácio mostram-se freqüentemente limonitizados sendo comum, nas barrancas fluviais do Rio Paraná, o avistamento de níveis de laterização e de interdigitações conglomeráticas. Segundo a mesma fonte, os solos predominantes na região são arenosos, espessos e resultantes da meteorização das rochas psamíticas que fazem 0 embasamento regional. Os arenitos do Grupo Bauru sucedem os do Grupo Caiuá e o conjunto desses arenitos, com mais de 200 m de espessura, constitui um registro fluvial cretácico. Na aloestratigrafia esse pacote sedimentar marca o pós-rifteamento do continente sul-americano (Milani,1997).

Morfologicamente, o Planalto Arenítico Basáltico, constitui extensa superfície aplainada, suavemente dissecada, onde predominam formas tabulares, com topo aplanado, com diferentes ordens de grandeza de aprofundamento de drenagem, separados por vales de fundo plano.

Para Almeida (1997), o uso do solo pode ser definido como "as diferentes formas de intervenção do homem no meio, com o objetivo de obter dele o atendimento de suas necessidades, quer sejam agrícolas, industriais, urbanas etc., através de técnicas e costumes que evoluem e se intensificam com o tempo". Segundo Sokolonsdin (1999), a classificação do uso da Terra leva em conta o tipo de uso de Terra da data do mapeamento, o manejo e a estrutura de produção, procurando com isso caracterizar da melhor forma possível as classes de uso definidas. As classes de uso da Terra podem ser definidas como unidades simples ou associações de classes, dependendo da 
área estudada e da escala de trabalho adotada. No entanto, em decorrência da demanda socioeconômica, tem-se verificado o uso inadequado dos recursos naturais por meio de diversos processos modificadores, os quais incluíram, por exemplo, a revolução verde e azul, correspondendo, respectivamente, às evoluções produtivas da agricultura e da pisicultura, além da revolução industrial, inserindo modificações nos recursos naturais.

Tendo em vista a visualização e interpretação previa do uso e ocupação do terrada Bacia, nos anos de 1966 e 2009 .

\section{Metodologia}

\section{Carta de Declividade}

A carta Clinográfica ou de declividade tem como objetivo quantificar a inclinação ou declive do terreno. Trata-se, de uma representação cartográfica do relevo de grande importância para ordenamento e a gestão ambiental. Pois, tais dados são imprescindíveis para a avaliação das possibilidades de ocorrência de processos de remobilização das formações superficiais ou de corpos rochosos, tais com escorregamentos, erosão, desmoronamentos, entre outros.

A análise da carta clinográfica permite evidenciar a distribuição das inclinações das superfícies do relevo, sendo esta característica muito importante quando da análise do uso e ocupação do solo da área, bem como de fluxo torrencial de superfície e os conseqüentes processos erosivos e arrastamento de materiais para o curso hídrico da bacia.

Por isso De Biasi (1992), salienta que a construção das cartas clinográfica constitui - se em excelente instrumento de análise muito utilizado nos trabalhos ligados ao Planejamento Urbano e Rural. 
Também Beltrame (1994), enfatiza que essas cartas são essenciais para o planejamento físico, pois tem grande influencia na quantidade da infiltração da água pluvial e na velocidade do escoamento superficial, contribuindo dessa forma para o aceleramento ou retardo dos processos geomorfológicos.

A fácil construção da carta de declividade baseia-se no exame da forma pela qual o relevo é representado nas cartas topográficas, desse modo, através de procedimentos matemáticos, que exigem a identificação da eqüidistância das curvas de nível e a distância horizontal ou espaçamento entre as curvas, é possível obter a declividade do terreno.

Segundo De Biasi (1992), os dados de declividade, em porcentagem, podem ser obtidos através da seguinte fórmula.

$$
\mathrm{D}=\mathrm{n} \times 100
$$

Onde:

$\mathrm{D}=$ Declividade, em porcentagem;

$\mathrm{N}=$ Eqüidistância das curvas de nível (desnível altimétrico)

$\mathrm{E}=$ Espaçamento entre as curvas de nível (distância horizontal).

Segundo Cunha (2001) a declividade de uma área constitui-se em um fenômeno continuo. Contudo, é impossível representar cartograficamente tal continuidade. A representação da declividade apresenta como problemática central à escolha de classes adequadas tanto ao objetivo do trabalho como ao local estudado.

Para a geração da Carta Clinográfica, será utilizada a metodologia de (De Biasi 1992), que consistem primeiramente na aquisição da Carta Topográfica do DSG (Diretoria do Serviço Geográfico), Folhas de Brasilândia e de Dracena, na escala de 1: 100.000, editadas em 1972, produto das fotos aéreas de 1966 na escala de 1: 60000, com eqüidistância de 40 em 40 metros; e a compilação das informações da Carta Topográfica através de escanerização em scanner Hp, calibrado com 300 de dpi de resolução. 
Para a construção da carta clinográfica, foi inicialmente determinada as classes de declividade, a partir da adaptação dos trabalhos elaborados por BATCHELDER (1950), SPIRIDONOV (1960), CAZABAT ( 1968), AGÊNCIA DE DEFESA (EUA) (1974), DE BIASI (1970) e LEPSCH (1991) e SILVA (2006).

Analisando as curvas de nível e utilizando a metodologia descrita por De Biasi (1992), que consiste no deslocamento através das diferentes curvas de nível da bacia, estabelecendo-se os limites das classes toda vez que cada classe encaixasse perfeitamente, sendo que foram elaboradas 11 classes de declividades para analisar de forma mais detalhada as características do relevo da bacia. No entanto, para facilitar o entendimento, optou-se em agrupá-las em seis classes, a partir da classificação de Lepsch (1991).

Estabelecidas às classes, o próximo passo, segundo a orientação de De Biasi (1970), foi à elaboração de um ábaco graduado com as medidas apresentadas pelo espaçamento das curvas de nível. Construído o ábaco, foram seguidas as recomendações do autor, que consistem no deslocamento deste através das diferentes curvas de nível. Observamos que não houve um grande aproveitamento através desta metodologia, pois a bacia é pequena, e por esse motivo mascarava os dados com a utilização do ábaco, devido a isso utilizamos o escalímetro para obtermos essas informações, com isso houve um melhor detalhamento das informações, pois através do uso do escalímetro pode-se obter uma melhor precisão deste levantamento.

Em relação às cores utilizadas para demarcar cada classe, considerou-se que com os reflexos de onda de luz, as cores exercem grandes influencia sobre as pessoas, provocando diversas reações emocionais e fisiológicas, tais como: apetite, ódio, excitamento, relaxamento, etc. Juntamente com os símbolos, traços e letras, as cores fazem parte dos mapas, devendo ajudar para uma composição harmoniosa de todos os seus elementos, não podendo, portanto, aparecer aleatoriamente, sem respeitar, ao menos, o bom senso e algumas regras básicas. Sendo assim e, seguindo a orientação de Duarte (1991), foi utilizada a rosa cromática, pois há uma combinação entre as cores frias e quentes. As cores frias denotam uma quietude e tranqüilidade, 
além de frescura. Elas criam à ilusão de profundidade, dando a impressão que se situam atrás dos planos que as contêm. Em mapas de relevo o verde colorindo as regiões mais baixas, passando depois para tonalidades de amarelo e marrom, com algumas variantes. O azul é uma cor que lembra o ar e a água, a pureza, simplicidade, frescura e calma, esta cor é utilizado para representar elementos hidrográficos, tais como: mangues, lagos, rios, etc... A cor violeta lembra ambientes frios, delicadeza, em mapas térmicos representa temperaturas muito baixas (por tal razão, podem aparecer em mapas de relevo representando regiões muitas elevadas).

As cores quentes são atraentes em razão dos efeitos de vivacidade, calor e alegria, são dinâmicas estimulantes. O amarelo por sua proximidade ao verde é a mais fria das chamadas cores quentes, em mapas, estão associadas com temperaturas quentes, baixas altitudes, clima áridos, vegetações herbáceas baixas densidades, e a cor laranja lembram dinamismo, prosperidade, alegria, excitação, é uma cor que dá a sensação de avanço do ambiente.

\section{Carta de Uso, Ocupação e Manejo da Terra da Bacia}

Segundo Almeida (1997) o uso do solo pode ser definido como "as diferentes formas de intervenção do homem no meio, com o objetivo de obter dele o atendimento de suas necessidades, quer sejam agrícolas, industriais, urbanas, etc., através de técnicas e costumes que evoluem e se intensificam com o tempo".

Com o crescimento e aumento de produção para atender as necessidades humanas, nova formas de plantio, criação e produção industrial foram estabelecidas, ocasionando o aumento crescente de poluentes, a modificação da paisagem e a fragmentação de ecossistemas.

Espíndola (2000) enfatiza que se verifica cada vez mais, a utilização do sensoriamento remoto como forma de avaliação, em macroescala, dos impactos ambientais, possibilitando, inclusive, uma análise histórica dos usos e 


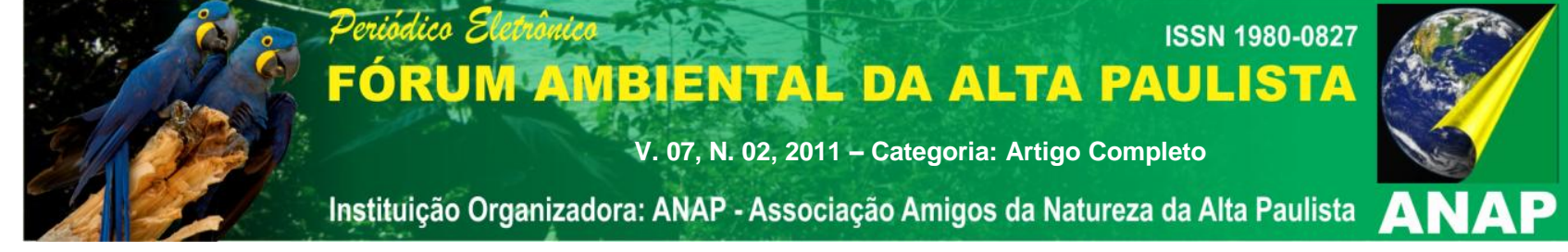

da ocupação, bem como uma previsão temporal e espacial em relação aos padrões atuais de desenvolvimento.

Segundo Novo (1992) as imagens de satélite são utilizadas na maior parte dos casos, para análise dos processos de uso e ocupação do solo de uma referida área e sua conseqüente influência na cobertura do solo.

Para ESPÍNDOLA (2000), o uso da bacia hidrográfica como unidade de planejamento nas investigações e no gerenciamento dos recursos hídricos originou-se da percepção de que os ecossistemas aquáticos são essencialmente abertos, trocam energia e matéria entre si, com os ecossistemas terrestres adjacentes, sofrem alterações de diferentes tipos em virtude dos usos do solo e das atividades antropogênicas nele desenvolvidas.

MACHADO (2001) salienta que a bacia hidrográfica tem sido adotada internacionalmente como unidade físico-territorial básica para o planejamento e a gestão de recursos naturais, principalmente hídricos. Sendo a água de um manancial o resultado da drenagem de sua bacia, sua qualidade e, portanto, suas características físicas, químicas, biológicas e ecológicas encontram-se sempre na dependência direta das ações (uso e ocupação) que se realizam no solo dessa bacia, bem como o grau de controle que se tem, sobre essas fontes.

O uso de recursos naturais, sua preservação e a recuperação de ecossistemas passam, sem duvida, por uma visão sistêmica e integrada da qual a bacia hidrográfica e uma unidade bastante importante e característica, ou seja, uma unidade biogeofisica bem determinada, dados seus contornos e delimitações relativamente precisos e seus mecanismos de funcionamento que dependem de subsistemas (ESPINDOLA, 2000).

A analise da nova evolução do uso e ocupação do solo desta bacia é ferramenta indispensável para avaliação e a inter-relação entre a ocupação antrópica atual e a capacidade de transporte de sedimentos desta área de estudo, para que a partir de então se determinem prioridades a um posterior processo de adequação desses usos para o melhor aproveitamento do solo, e 
conseqüentes preservações da qualidade dos elementos biofísicos que estão contidos em uma bacia hidrográfica.

\section{Recuperação das Matas Ciliares e das Feições Erosivas da Bacia do Bom Jardim/ Brasilândia-MS}

O planejamento participativo constitui estratégia fundamental para a busca da cumplicidades na realização de intervenções territoriais, pois os atores sociais são peças que dependendo de suas ações podem promover o sucesso ou o insucesso das intervenções que podem ser públicas ou privadas, ou até nascerem da mediação de interesses das duas partes. Como é o caso, do Plano de Recuperação das Matas Ciliares e das Feições Erosivas da Bacia do Córrego Bom Jardim, localizado no município sulmatogrossense de Brasilândia, que surgiu de interesses múltiplos da Prefeitura municipal, por pressão da promotoria pública, dos fazendeiros que por sua vez estão sendo pressionado pelos frigoríferos do estado de São Paulo, que passaram a exigir para 2012, certificação ambiental da propriedade. E da CESP, que cobra dos proprietários da bacia, a preservação das matas ciliares e o uso de práticas e manejos conservacionistas da terra, visando a redução da elevada carga de sedimentos que estão assoreando a RPPN Cisalpina, de sua propriedade.

Para a operacionalização do plano, foram realizadas diversas reuniões previas entre os parceiros, Prefeitura Municipal de Brasilândia, CESP, Ministério Público, Sindicato dos Produtores Rurais de Brasilândia e a UFMS, Campus de Três Lagoas. Decidindo-se pela construção participativa, envolvendo todos os seguimentos da sociedade e usuários da bacia, pois o reflorestamento, em si é atividade de fácil realização, porém a manutenção das mudas, o cercamento, a realização de acerro, necessitariam do auxilio de todos.

Para a construção do plano, este foi subdividido em quatro fases: diagnóstico socioambiental, realização de oficinas de sensibilização, construção, consolidação e implementação e acompanhamento (gestão). 
Visando subsidiar o plano, com informações e cumplicidade de agentes sociais e econômicos, que dificilmente participariam das oficinas, optou-se pela realização dos instrumentos Delfos. Que abrangem perguntas sobre as potencialidades, problemas e visão de futuro, enfatizando o uso do solo com a pecuária, a opção do eucalipto e a necessidade de recomposição das matas ciliares e das feições erosivas da Bacia.

A fim de apresentar à população a real situação ambiental presente na subbacia em questão e sensibilizar a sociedade organizada sobre as degradações ambientais da bacia devido ao seu uso, ocupação e manejo não sustentável, que além de ferir a legislação ambiental, que causam fortes impactos a qualidade da bacia e de vida da população.

Tal sensibilização tem como objetivo alertar a população para a necessidade de se agir em parceria, a fim de se estabelecer condições ambientais favoráveis à vida humana sustentável, que possam ao mesmo tempo inverter a situação ecologicamente insustentável presente atualmente na subbacia do córrego Bom Jardim e melhorar seu enquadramento perante a classificação CONAMA 357/2005.

$\mathrm{Na}$ oficina de construção do Plano, pretende-se desenvolver a visualização de situações futuras, estabelecimento de projetos, objetivos e metas a serem atingidos, ações a serem implementadas, prazos a cumprir, responsáveis pelas ações, para o reflorestamento das matas ciliares, das feições erosivas e possivelmente, do fomento ao emprego de práticas conservacionistas de uso da terra e de seu ordenamento.

Tem por intuito elaborar estratégias pertinentes à plena realização e concretização do plano participativo após anterior diagnóstico dos problemas encontrados na área buscando assim soluções viáveis à efetiva realização das propostas para melhora das condições atuais.

A oficina de construção na subbacia do córrego Bom Jardim divide-se em várias etapas e a primeira delas é o levantamento dos problemas, potencialidades, oportunidades e ameaças, considerando que: problemas são situações incorretas, reais e não aceitas ou ainda fatores que interrompem o 
desenvolvimento do plano. Potencialidades são situações positivas, não aproveitadas ou pouco exploradas, ou fatores existentes que podem ajudar ou facilitar no desenvolvimento do plano.

Na fase de implementação é feita a projeção de situações futuras e a construção das metas que vão nortear o plano. Essa fase baseia-se na realização da oficina de construção e consolidação do plano realizadas anteriormente onde os participantes visualizam as situações futuras que eles desejam para o sistema e constroem o plano, estabelecendo os projetos, objetivos e metas a serem atingidos, ações a serem implementadas/implantadas, prazos a cumprir e responsáveis pelas ações.

A próxima fase é a de Implantação do Plano, onde é feita a divulgação do plano para a comunidade local e para o município que a bacia esta inserida, é executada compartilhada o plano.

A última fase é a de Gestão, onde será feito o gerenciamento, controle, avaliação e ajuste e/ou replanejamento, a partir da criação de comitê de gestão, cooperativas, associações, etc. Vale ressaltar que nessa fase à legislação estabelecida por órgãos competentes como a ANA - Agência Nacional das Águas, CONAMA - Conselho Nacional de Meio Ambiente, Código Florestal, Plano Diretor Municipal, Lei Orgânica do Município, Legislação Estadual, etc., devem ser respeitados.

A gestão deve ser feita pela própria comunidade local, considerando que o processo de planejamento participativo fornece aos participantes condições para a gestão. Já que as decisões foram tomadas pela própria comunidade.

\section{Resultados e discussões}

Cartas morfometrias de Declividade e uso e ocupação do solo e Recuperação das Matas Ciliares e das Feições Erosivas 


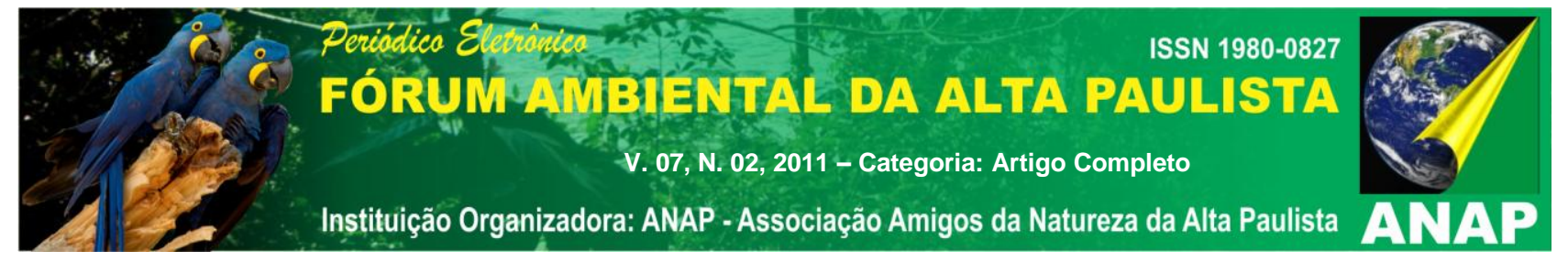

Como resultado dos estudos de declividade, foi construída a carta de declividade, com o auxílio da carta de base e do programa Auto CAD 2008, Figura 2.

$\mathrm{Na}$ bacia do Bom Jardim, em áreas com classes superiores a 3\% de declividade, verificam-se feições erosivas, mostrando a eficiência da metodologia de Ramalho Filho e Beek (1995), a necessidade de práticas conservacionistas de uso do solo, para conter a grande perda de solos que ocorre na bacia.

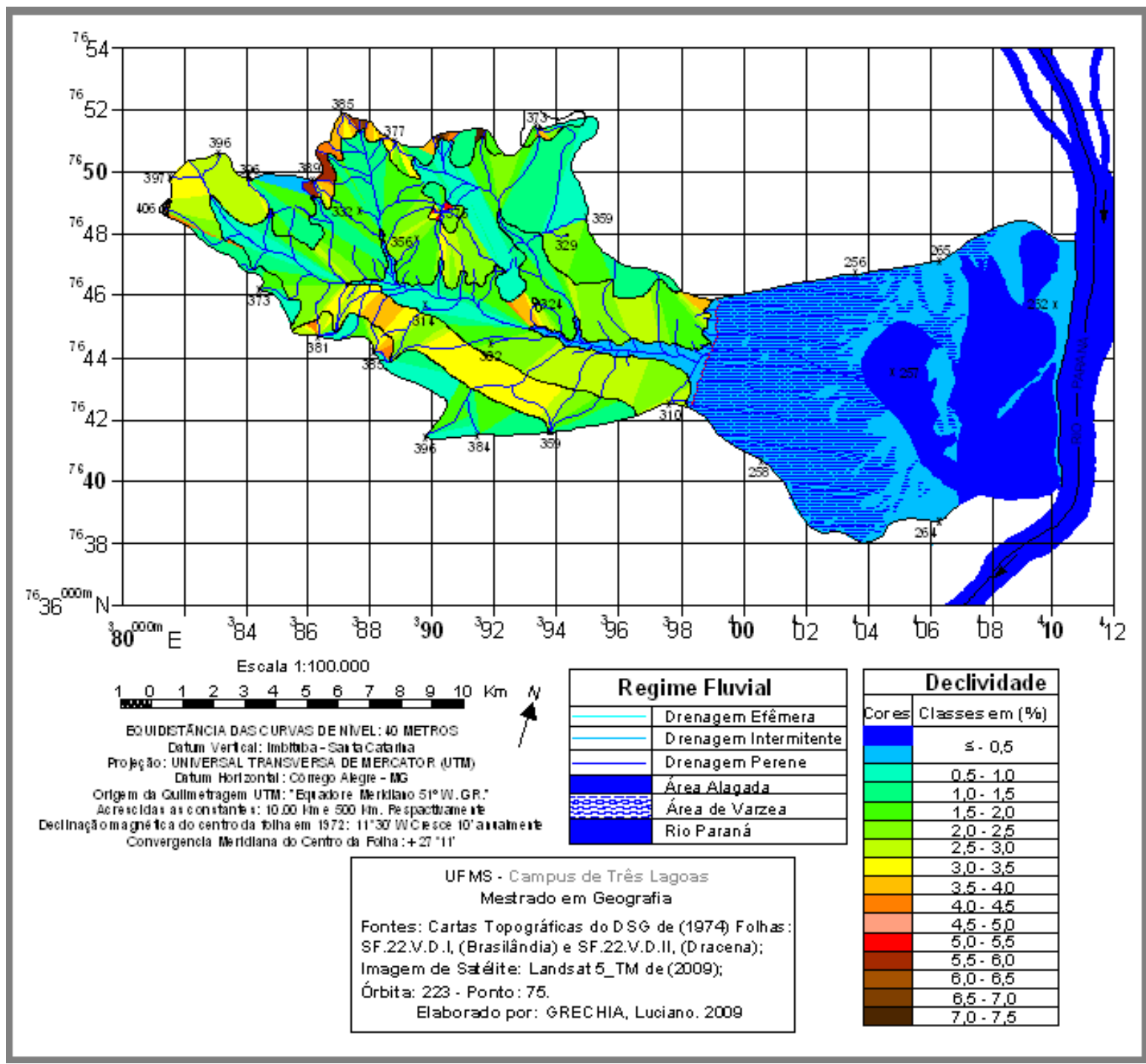

Figura 2- Carta de uso e ocupação da Bacia do Córrego Bom Jardim/MS, Brasilândia/MS. 


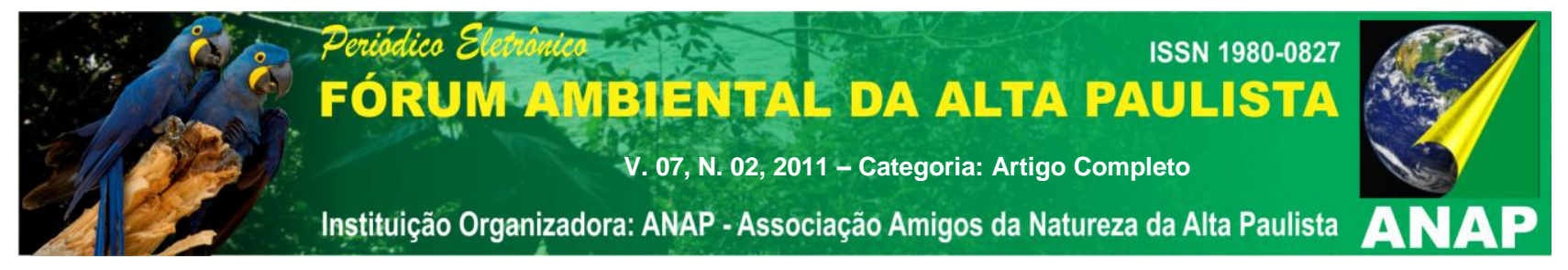

$\mathrm{Na}$ analise feita na carta de uso e ocupação do solo pode observar que a quase nenhuma existência de mata ciliar, figura 5, o único ponto que podemos observar a existência de vegetação é na Fazenda campanário onde localiza uma reserva legal e presença de mata ciliar, como apresenta a figura 3.

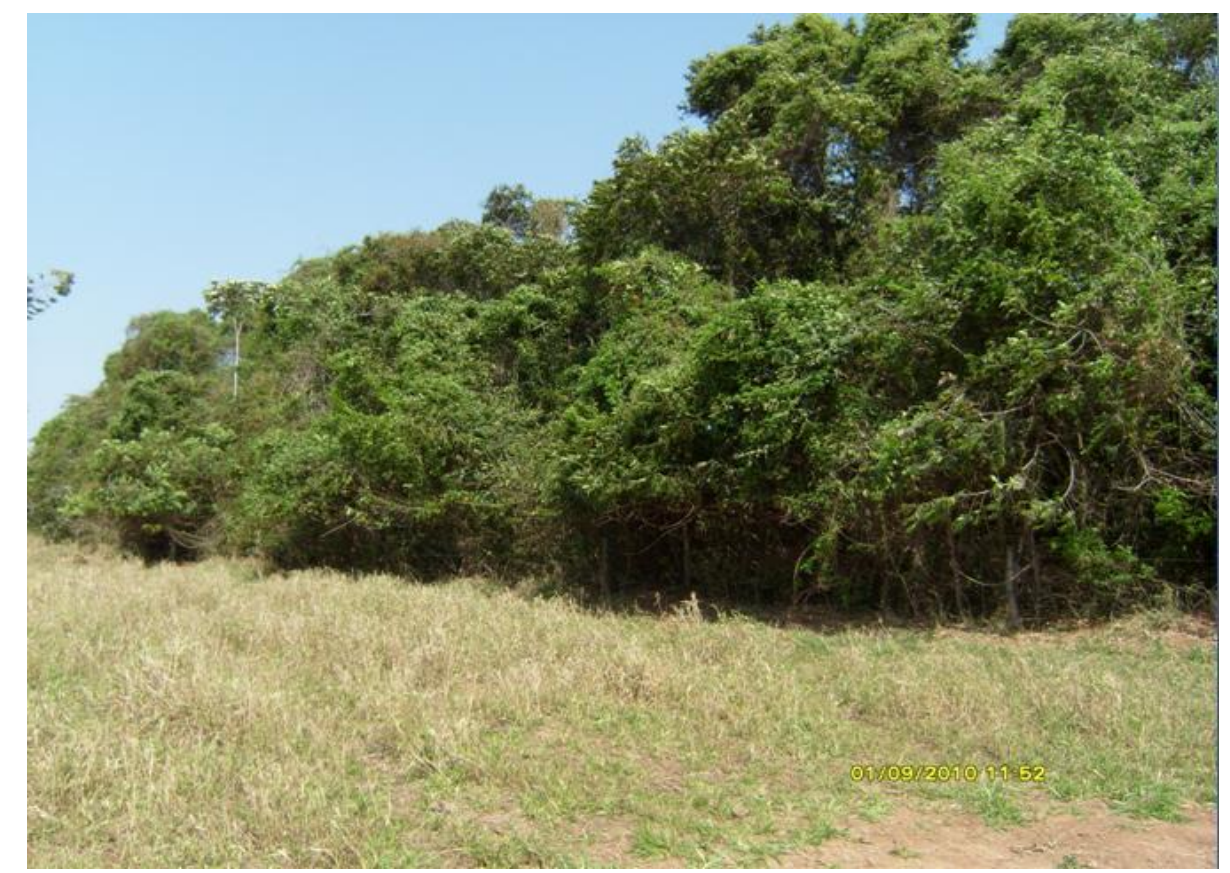

Figura 3: Reserva legal, na fazenda campanário, Bacia do córrego Bom Jardim Brasilâdia

Destaca- se também em toda bacia área de pastagem, principal cultura do lugar, que facilita erosões na época de cheias pois é quando as pastagens ficam ralas e secas, com pisoteio do gado só tende aumentar as erosões, como já podemos observar na bacia, e nos mostra na figura 4. 

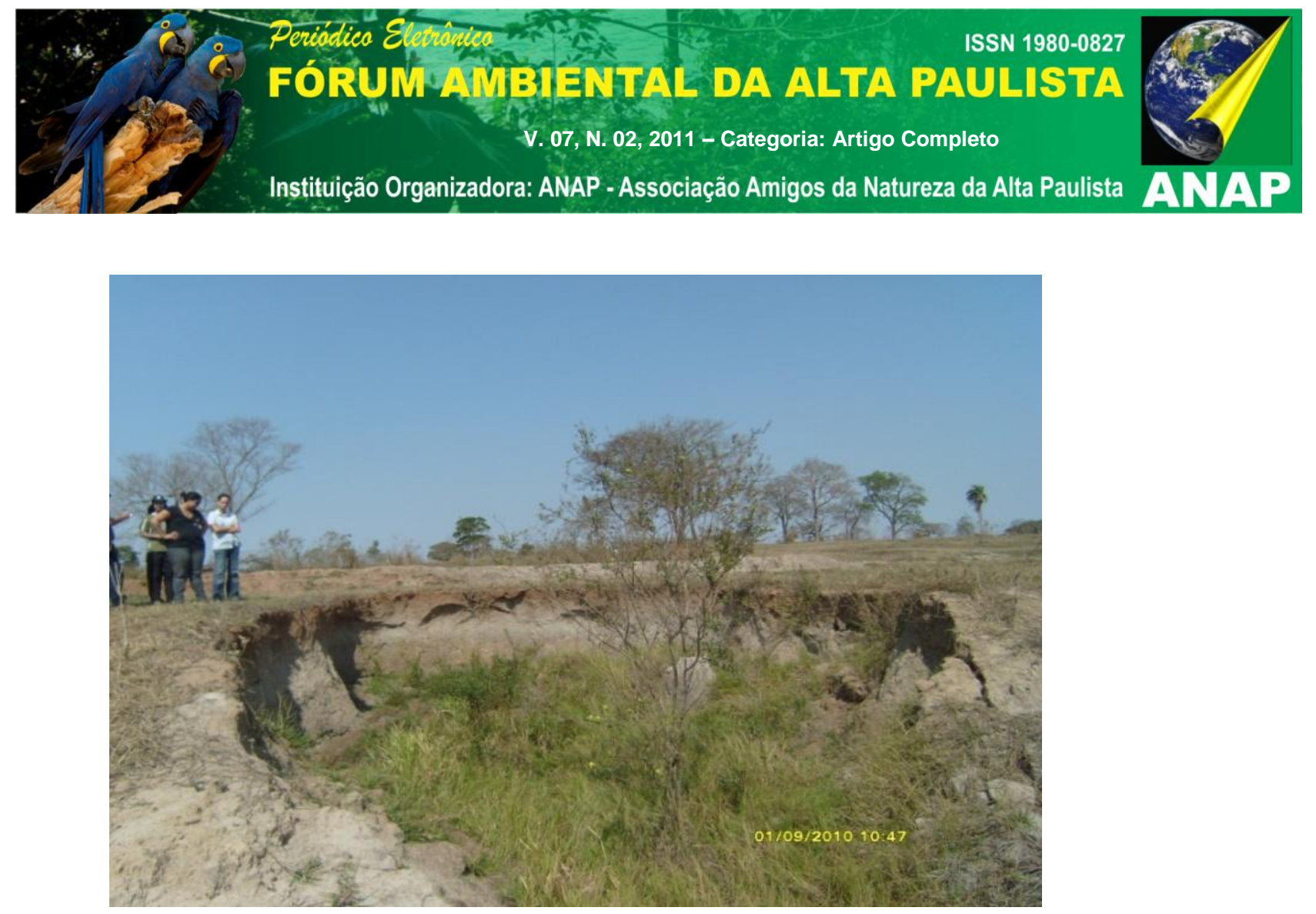

Figura 4: Feições erosivas na Bacia do córrego Bom Jardim Brasilândia 

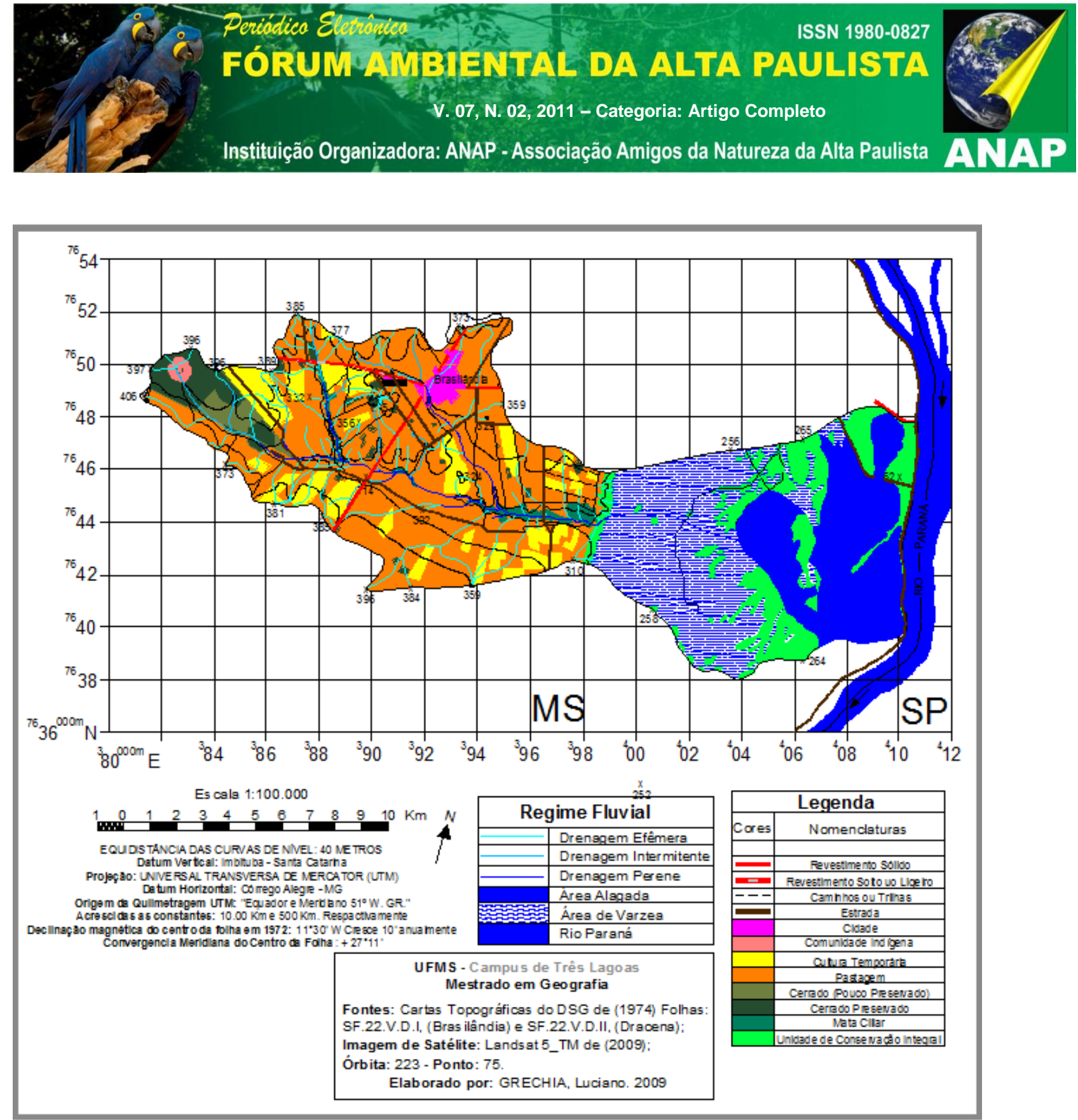

Figura 5: Carta de uso e ocupação do solo da Bacia do Córrego Bom Jardim/MS, Brasilândia/MS.

Depois de serem feitas todas as analises para verificar os maiores problemas da bacia, iniciou- se então o plano de recuperação onde o primeiro passo foi a realização das primeira oficinas de sensibilização, ocorrida no plenário da Câmara de Vereadores do município de Brasilândia, figura 6. 0 projeto ainda esta em andamento, e há muita expectativas para recuperação da área. 

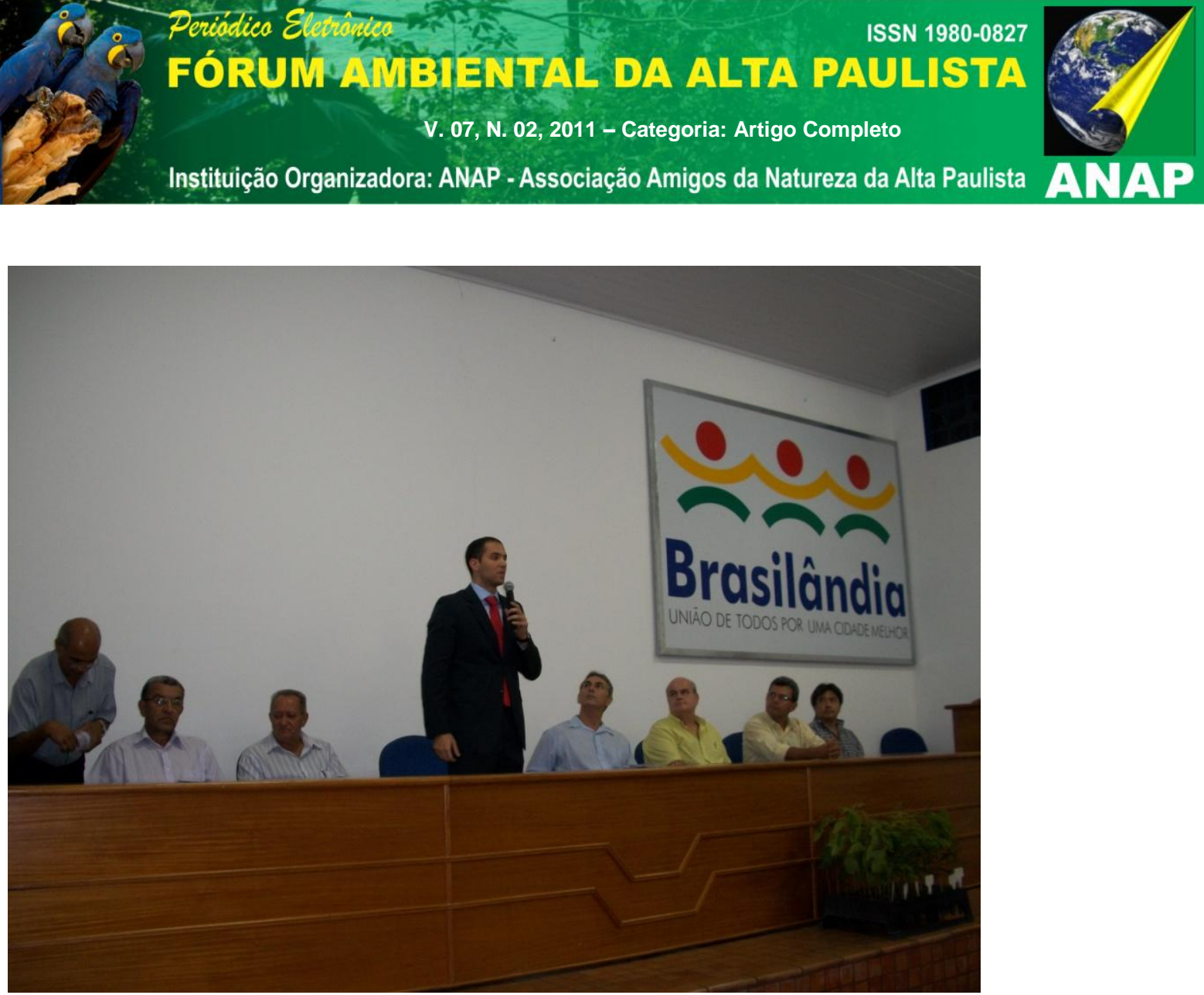

Figura 6 - Discurso do Promotor de Justiça de Brasilândia, Dr. Jui Bruno Nogueira.

\section{Considerações Finais}

Depois de todas as analises feitas na bacia, podemos observar que 0 plano de recuperação da mesma deve ser aplicado o mais rápido possível, assim como vimos que pelo menos o primeiro passo já foi iniciado, agora cabe aos órgãos públicos e aos fazendeiros a consciência principalmente de preservar a natureza.

A perda da vegetação e a conversão do terreno a outros usos podem repercutir negativamente nas bacias hidrográficas. A falta de cobertura vegetal e de curva de nível faz com que o impacto da água da chuva cause deslocamentos superficiais no solo levando os sedimentos para o fundo do rio ou para reserva legal como acontece no córrego Bom Jardim sedimentos que são Lançados na RPPN Cisalpina. 


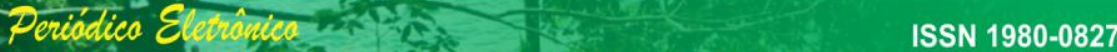

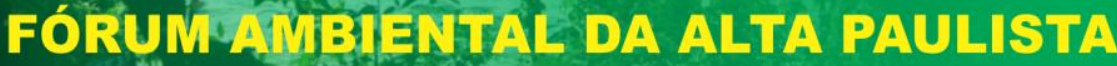 \\ V. 07, N. 02, 2011-Categoria: Artigo Completo \\ Instituiç̧ão Organizadora: ANAP - Associação Amigos da Natureza da Alta Paulista}

As nascentes e as margens dos rios quando protegidos evitam a erosão e mantêm a vazão da água.

A falta de cumprimento da legislação quanto a praticas conservacionistas das reservas legais são os problemas centrais ocorrentes na bacia e que devem receber toda atenção no Plano Diretor e no Plano Diretor das Águas do município de Brasilândia. Propoem-se a recomposição da cobertura vegetal tanto de mata ciliar quanto de reserva legal em toda a bacia para que haja uma redução no transporte e maior infiltração da água da chuva ao nível das raízes.

\section{Referência}

ANA - Implantação da Prática de Gerenciamento Integrado de Bacia Hidrográfica para o Pantanal e Bacia do Alto Paraguai ANA/GEF/PNUMA/OEA: Programa de Ações Estratégicas para o Gerenciamento Integrado do Pantanal e Bacia do Alto Paraguai: Relatório Final/ Agencia Nacional de Águas - ANA [et al]. - Brasília: TDA Desenhos \& Arte Ltda, 2004.

BARBOSA, L.M.; ASPERTI, L.M.; BEDINELLI, C.; BARBOSA, J.M.; ZEIGLER, T.I. Estudos sobre o estabelecimento e desenvolvimento de espécies com ampla ocorrência em mata ciliar. Revista do Instituto Florestal, v.4, p.605-608, 1992.

BARRETTO, M. Planejamento e Organização em Turismo. Campinas, SP: Papirus, 1991.

BUARQUE, S. Metodologia e Técnicas de Construção de Cenários com Foco Microrregional. Recife: IPEA, junho, 2000.

CAPPI, Nanci. Influência do Uso e Ocupação do Solo nas Concentrações de Nitrato nas Águas Subterrâneas das Bacias dos Córregos Fundo e Santa Maria, Aquidauana - MS. Qualificação (Mestrado em Geografia) Universidade Federal de Mato Grosso do Sul, Campus Universitário de Aquidauana, Aquidauana, 2002: 114 p.

CASSETI, V. Elementos de Geomorfologia. Goiânia: Editora de UFG, 1994.

CHORLEY, R.J.; KENNEDY, B.A. Physical geography - A Systems Approach. London: Prentice Hall International, 1971.

CHRISTOFOlETTI, A. Geometria Hidraulica. São Paulo: Noticia Geomorfologica, 1976, 16 (32): $3-37$.

CHRISTOFOLETTI, A. "Geometria dos Canais Fluviais”. Geomorfologia Fluvial. São Paulo: Edgard Blucher, 1976:53 - 92 P.

CHRISTOFOLETTI, A. Aplicabilidade do Conhecimento Geomorfologico no Projetos de Planejamento. In: GUERRA, A.J.T.; CUNHA, S.B.C (org.) Geomorfologia - Uma Atualização de Base e Conceitos. Rio de Janeiro: Bertrand Brasil, 1995. 


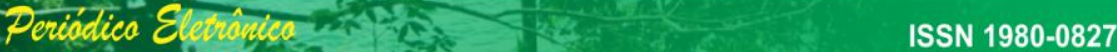 FÓRUN AVIJ JWAL DA ALTA PAULISTA \\ V. 07, N. 02, 2011-Categoria: Artigo Completo \\ Instituiç̧ão Organizadora: ANAP - Associação Amigos da Natureza da Alta Paulista}

CHRISTOFOLLETTI, Antônio. Geomorfologia. São Paulo, Edgard Blücher, 2ª edição, 1980.

CUNHA, Cenira Maria Lupinacci. A Cartografia do Relevo no Contexto da Gestão Ambiental. Tese (Doutorado). Universidade Estadual Paulista; Instituto de Geociências e Ciências e Exatas. Rio Claro, 2001.

DANTAS, O. O Planejamento como Instrumento de Desenvolvimento Regional: 0 Caso do Plano Regional de Desenvolvimento da região Sul-Fronteira_. Dissertação de Mestrado em Geografia, UFMS, Campus de Aquidauana, 2004.

DE BIASI, Mário. A Carta Clinográfica: Métodos de Representação e sua Confecção. Revista do Departamento de Geografia. USP. Faculdade de Filosofia, Letras e Ciências Humanas. P. 47 - 53. 1992.

ESPÍNDOLA, E.L.G. et. al. - A Bacia Hidrográfica do Córrego Monjolinho. RIMA. USPEscola de Engenharia de São Carlos. São Carlos, 2000.

FAIRBRIDGE, R.W. (ed.) The Encyclopedia of Geomorphology. New York: Reinhold Book Corporation, 1968.

GOMES, M.A.F. et.al. Uso Agrícola das Áreas de Recarga do Aqüífero Guarani: localizadas na porção Noroeste e parte oeste da bacia sedimentar do Paraná. Jaguariúna: Embrapa Meio Ambiente, 1999.27p. (Documento, 08).

GRECHIA, L.; Dinâmica Geomorfologica da Bacia Hidrográfica do córrego Bom Jardim, Brasilândia/MS. Dissertação de mestrado - Fundação Universidade Federal de Mato Grosso do Sul, Brasil. 2011.

HACK, J.T. Interpretation of Crosional Topography in Humid Temperate Regions: Am.Jour. Sci., v. 258-A, 1957: $69-97$ p.

HATCHER, R. D. Structural Geology. , Prentice-Male. 1995:525 p.

HORTON, ROBERT E.; "Erosional Development of Streams and their Drainage Basins: hydrophysical approach to quantitative morphology", Geol. Soc. América Bulletin 1945, 56 (3), $275-370 \mathrm{p}$.

KNIGHTON, A. D."Variation in Width - Discharge Relation and Some Implications for hydraulic Geometry". Geol. Soc. American Bulletin, 1974, 85(7): 1.069 - 1.076 p.

KNIGHTON, A. D."The Adjustment of Channel Form". Fluvial Forms and Processes. New York: Edward Arnold, 1984:151 - 260 p.

KNIGHTON, A. D. "Channel form". In. Fluvial Forms and Processes: a New Perspective. New York: John Wiley e Sons, 1998:151 - 260 p.

KRAUSE, F.; COLLINS, H. N.; NELSON, D. A.; MACHERMER, S. D. \& FRENCH, P. R. Anatomia multiescalar de um reservatório. AAPG/Canadá. Bulletin 71/1987. p.1223-1260.

LEOPOLD, L. B. e WOLMAN, M.G., e MILLER, J.P., Fluvial Processes in Geomorphology, W. H. Freeman \& Co., San Francisco, EUA, 1964. 


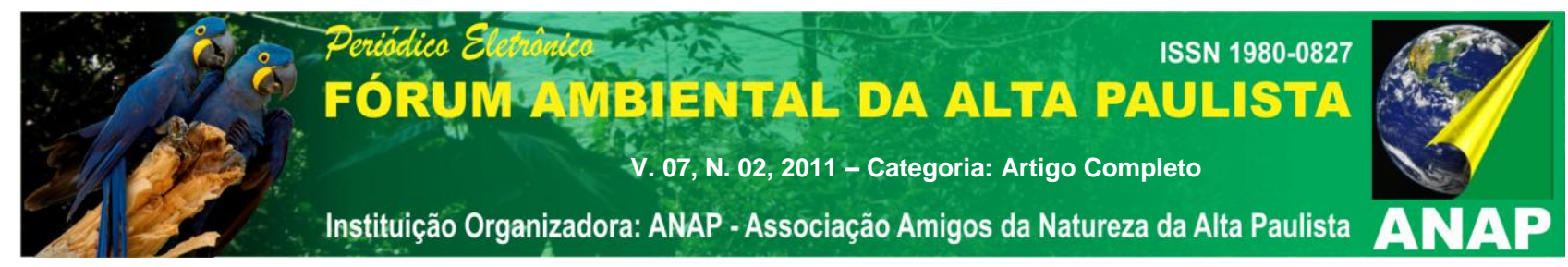

MACHADO, P. J, de O. Recursos Hídricos: Uso e Planejamento. GEOSUL: Revista do Departamento de Geociências/Universidade Federal de Santa Catarina. Centro de Filosofia e Ciências Humanas. V. 16, n.ำ 31, P. 103-115, jan/jun. 2001.

MARTINS, S. R. O. Desenvolvimento Local: questões conceituais e metodológicas._Revista Internacional de Desenvolvimento Local. Vol. 3, N.5, p.51-59, Set. 2002.

MATO GROSSO DO SUL Plano Regional de Desenvolvimento Sustentável do Alto Pantanal. SEPLAM/MS. Campo Grande, 2003: 186p.

MATTOS, S. H. V. L. de; PEREZ FILHO, A. Inter-relações entre sistemas fisico-naturall e sócio-econômico e qualidade ambiental na bacia hidrográfica do córrego do Piçarrão (Campinas - SP). Anais do XV Simpósio Brasileiro de Geografia Física Aplicada. USP, 2005.

MAURO, C. A. et al. Contribuição ao planejamento ambiental de Cosmópolis - SP - BR. In: Encuentro de geógrofos de América Latina, 3, 1991. Toluca. Memórias... Toluca: UAEM, v, 4, 1991, p $391-419$.

MENDES, J.C.; PETRI, S. Geologia do Brasil. Rio de Janeiro: Instituto Nacional do Livro, v.9 1971, 207p.

MIALL, A. D. The Geology of Fluvial Deposits. 1996, Springer-Verlag, $582 \mathrm{p}$.

Universidade Federal do Rio Grande do Sul - UFRGS.(1997), 255p.

OLIVEIRA, P. T. T. M.; VIEIRA, T.V. \& CUNHA, S. B. (1998). "Modificações na rede de drenagem, ocasionados pelo aumento da urbanização na cidade de Teresópolis - RJ". In: II Simpósio Nacional de Geomorfologia. Universidade Federal de Santa Catarina. Florianópolis - Santa Catarina.

PINTO, A. L. Saneamento Básico e sua Implicações na Qualidade das Águas Subterrâneas da Cidade de Anastácio (MS). 1998. 175p. Tese (Doutorado e Geociências) Universidade Estadual Paulista/Instituto de Geociências e Ciencias Exatas, Rio Claro, 1998.

PINTO, et.al, (2003).Implicações, Uso e Ocupação e Manejo Rural e Urbano na Qualidade de Águas Subterrâneas da Depressão do Rio Aquidauana SC". In: V Encontro Nacional da ANPEGE. Florianópolis - Santa Catarina.

PINTO, A. L., CARVALHO, E. M de, SILVA, P. da. Contribuição do subsistema biofísico e sócio-produtivo no planejamento territorial e gestapo ambiental da bacia do Córrego Fundo. In: VI Encontro Nacional da ANPEGE. Fortaleza, 2005. Anais.... Fortaleza: UFC, 2005.

PORTUGUEZ, A. P. Pressupostos para a Gestão Participativa do Turismo com Base Local. Espaço - Geografia, Departamento de Geografia da UNB e Programa de Pós-Graduação em Geografia. Ano 2, №1 (1999), 111- 119 - Brasília: Instituto de Ciências Humanas, Universidade de Brasília, 1998

REIS NETO, José Francisco. Planos de Desenvolvimento do Estado de Mato Grosso do Sul:Investigação dos Seus Atributos Relevantes.Dissertação de Mestrado. UFRGS/PPGA, Porto Alegre-RS, 2000.

ROCHA, J.D.; BURSZTYN, M.A. A Importância da Participação Social na Sustentabilidade do Desenvolvimento Local. In: Revista Internacional de Desenvolvimento Local. Vol.7, N.11, p45-52, Set. 2005. 


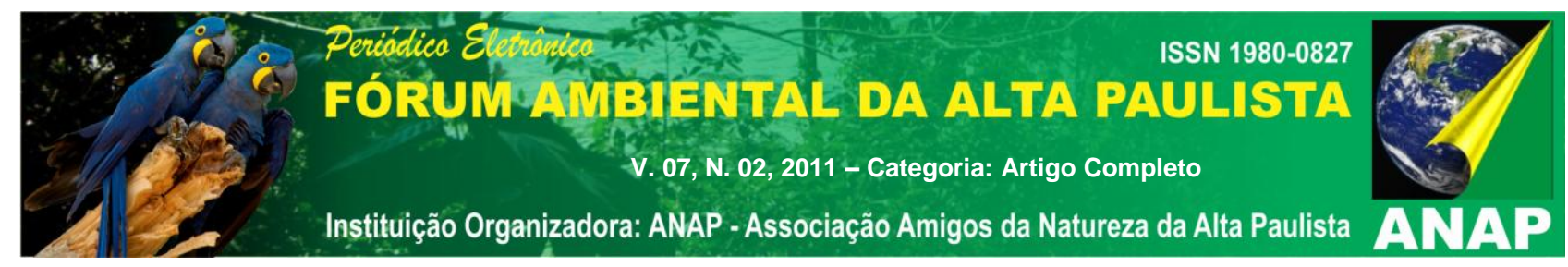

ROCHA, O; PIRES, J. S. R.; SANTOS, J.E. dos. A bacia hidrográfica como unidade de estudo e planejamento. In: A bacia Hidrográfica do Rio Monjolinho: Uma abordagem Ecossistêmica e a visão interdisciplinar. São Paulo: Rima, 2000. p.1-16.

SALA, M. \& INBAR, M. (1992) "Some Hydrology Effects of Urbanization in Calatan Rivers”. In: Catena. Vol. 19, nº. 1, pp. 19-31.

SANT'ANNA NETO, J. L. O Caráter Transicional do Clima e a Diversidade da Paisagem Natural na Região de Aquidauana. In: II Semana de Estudos Geográficos: Desenvolvimento e Geografia 2., 1993, Aquidauana. Anais... UFMS/CEUA, v.1 1993. P.118-128.

SANTOS, J.A. Análise da Ocupação da bacia do rio Huatnay (Cuzco-Peru) utilizando técnicas de geoprocessamento. Rio Claro, 1998, Dissertação (mestrado em Geociências Unesp, Rio Claro, São Paulo (no especial), 125-30, 1990.

SANTOS, Luiz Carlos Araújo dos. Estudo da Bacia do Rio Paciência - MA por meio da análise cartográfica. Qualificação (Mestrado em Geografia) Universidade Estadual Paulista. Faculdade de Ciências e Tecnologia, Campus de presidente Prudente, 2001.

SHREVE, RONALD. L. "Variations of mainstream length with basin area in river networks", Water Resources Research (1974), 10 (6): 1167-1177.

SPIRIDONOV, A.I.. Princípios de la metodologia de las investigaciones de campo y el mapeo geomorfológico. Havana: Universidad de la Havana, Facultad de Geografia, 1981. 3V.

STRAHLER, ARTHUR, N.; Hypsometric (area - altitude) analysis of erosional topography, Geol. Soc. America Bulletin (1952), 63, pp. 1117 - 1142.

TRICART, J. A. A Geomorfologia nos Estudos Integrados de Ordenação do Meio Natural. In: Boletim Geográfico. Rio de Janeiro, out./dez, 1976.

ZACHARIAS, A. P. Metodologias para elaboração de cartas morfométricas em meio digital. 2000. Dissertação (mestrado) - Pós-graduação em Geociências, Universidade Estadual Paulista, Rio Claro, 2000.

ZAKIA, M. J. B. Identificação e caracterização da zona ripária em uma microbacia experimental: implicações no manejo de bacias hidrográficas e na recomposição florestal. Dissertação (doutorado) - Escola de Engenharia de São Carlos, Universidade de São Paulo. São Carlos, 1998 